Original Article

\title{
Correlates of Knowledge, Attitude and Practices about Health Care Waste Management among Hospital Workers of Pakistan
}

\author{
Ramesh Kumar, Ratana Somrongthong, Jamil Ahmed, Amer Jebril Almarabheh
}

\begin{abstract}
BACKGROUND: Healthcare waste is considered as neglected public health problem in developing countries.

OBJECTIVES: We aimed this study to explore the factors affecting the Knowledge, attitude and practices of health workers regarding healthcare waste management (HCWM) in Pakistan.

METHODS: Cross sectional study was done in two major public-sector hospitals in Pakistan. Validated, pre-structured questionnaire used to interview 275 physicians, nurses and other auxiliary staff after taking written consent. The sample size was selected according to the proportional size of the each HCW after sample size calculation for their equal representation from all the healthcare workers groups.

RESULTS: The responses to 24 questions for knowledge, 12 questions for attitude and 20 for practice were used to create three respective dependent variables for analysis to measure independent association of socio-demographic factors on the health workers' knowledge, attitude and practice. Younger workers, males and paramedics were statistically significantly less likely to achieve mean score on knowledge and HCWM practices $(P=<0.05)$. Operation theatres workers as compared to other departments were 25 times more knowledgeable and had better practices $(P=<0.05)$. Paramedical staff was more knowledgeable and had better practices while handling the healthcare waste as compared to physicians and nursing staff $(\mathrm{P}=<0.001)$. Physicians had positive attitude as compare to paramedics and nursing staff $(P=<0.001)$. Workers with $5-10$ years of experience were 4 times more likely to have positive attitude about HCWM $(P=<0.02)$.

CONCLUSION: The occupation was statistically significant factors affecting the Knowledge, attitude and practices among doctors, paramedics and nurses.
\end{abstract}

KEYWORDS: Healthcare waste, management of waste, behaviour of workers, hospital and health staff.

This article may be cited as: Kumar R, Somrongthong R, Ahmed J, Almarabheh AJ. Correlates of Knowledge, Attitude and Practices about Health Care Waste Management among Hospital Workers of Pakistan. J Liaquat Uni Med Health Sci. 2018;17(01):01-7. doi: 10.22442/jlumhs.181710541

\section{INTRODUCTION}

Globally, infectious waste is produced mainly by hospitals, which poses enormous environmental and public health challenges. This healthcare waste management (HCWM) continues to remain a major public health concern worldwide. Hence, proper disposal of healthcare waste using modern methods is highly recommended ${ }^{1}$. Hospital waste is known as second most dangerous waste in the world that should be managed properly by well skilled staff. Hospital waste is produced during the patient care, in clinics, maternity homes and research institutes ${ }^{2}$. Currently, there has been renewed focus by the patients, communities and providers about the management of healthcare waste all over the world ${ }^{3}$. Poor handling of healthcare waste contributes to significant morbidity and mortality, especially among children, in developing countries ${ }^{4}$. Healthcare waste includes all the waste generated by healthcare facilities, research institutions, clinics, maternity homes and laboratories.
The type of waste produced varies on numerous elements such as existing waste management methods, healthcare organization, services in the hospitals, patients load, and latest technology used during the medical procedures, number of reusable items employed in healthcare centres, and number of patients treated on daily bases. About two thirds of the medical waste is non-medical including, domestic waste generated by the patients and one third of such waste is infectious and requires special disposal. Though, this is a small quantity of healthcare waste generated within the hospitals, but its disposal and proper management is a complex task and requires additional resources because it can pose risk of infection to hospital workers, patients and their attendants. Exposure to infectious waste can transmit infections such as, Hepatitis B and C, HIV and other viral infections through contaminated sharp instruments and other material ${ }^{5}$. Other challenges posed by infectious waste include prolonged hospital 
stay, infertility, genital deformities, hormonally induced cancers, mutagenicity, dermatitis, asthma and neurological disorders in children(3). Poor HCWM practices by medical professionals also contributes to environmental pollution because hospital waste dumped within the hospital premises is often set on fire and results in generation of harmful chemical in the air. HCWM practices such as waste collection, storage, handling, segregation and disposal are generally reported to be below par the global standards and those of World Health Organization (WHO) in developing countries like India, China and Bangladesh. There are more than 22 of these countries where WHO assessments have consistently showed almost similar results ${ }^{6}$.

Each step of HCWM requires proper methods and guidelines. Hence, mismanagement at any of these steps would lead to a drastic failure in the whole cycle of waste management ${ }^{7}$. Overall, segregation is the main step in the hospital where the process of separation of medical and non-medical waste starts by the waste handlers; which is often ignored by the hospital staff ${ }^{8-10}$. Waste handling practices among health workers in hospitals in Pakistan fail to comply with the standards. Factors like; levels of education and experience in relevant fields have been shown to associate with knowledge, attitude and practices (KAP) among health workers in hospitals ${ }^{11,12}$.

There is need to explore and identify the pertinent correlates of improper HCWM in order to inform hospitals and other health institutions in developing countries for better handling of healthcare waste(4). However, little is known about the multiple factors and their correlates responsible for poor KAP about HCWM among healthcare workers in developing countries, including Pakistan. This study has explored different factors that could be addressed while effectively running HCWM system in hospitals in developing countries and other similar settings. In this survey study, we present the findings of KAP for HCWM from two major hospitals in Pakistan.

\section{METHODOLOGY}

\section{Study Design and Settings:}

This cross-sectional study was conducted after ethical approval from Research Ethics Committee of Health Services Academy, Pakistan (F.No.3-107/2013-IERC/ HSA); while institutional (gate keeper) permission was taken from the respective head of both hospitals located in Rawalpindi Pakistan. We used a modified, pretested and validated, piloted World Health Organization (WHO) tool. The internal consistency of this questionnaire was measured through Cronbach alpha for attitude and practice (0.92) and Kuder-Richardson (K-R 20) for knowledge $(0.81)^{13}$.

\section{Sampling:}

Sampling population includes different health workers including physicians, nurses, paramedics and sanitary workers. The sample size $(n=275)$ was calculated by using the $80 \%$ power, 0.05 alpha with $20 \%$ difference. In next stage participants were selected randomly from list of employees obtained from administration of both hospitals and were invited for voluntary participation in the study. Only those having regular govt service were included, however medical students, house officers and trainee physicians were excluded from sampling population.

\section{Data collection:}

Self-administered questionnaire was used to collect data; we also translated it into local language for sanitary workers. Data collectors were selected from the other city and were trained by the principal investigator.

\section{Ethical Consideration:}

Research Ethics Committee of Health Services Academy, Pakistan (F.No.3-107/2013-IERC/HSA) approved the study; while institutional permission was also taken from the heads of both hospitals located in Rawalpindi Pakistan.

\section{Data Analysis and Study variables:}

For statistical analysis three dependent variable were created from 24 statements on knowledge, 12 on attitude and 20 on practice to measure their correlation with socio-demographic factors of health workers. The mean score of responses were calculated and finally grouped at different levels. First, for instance, 24 variables assessing knowledge were added together through compute function within the Statistical package for social sciences version 18 to create a composite variable of knowledge. It was then categorised for the Logistic regression analysis into 0 and 1 ; code 0 was given to those participants who scored less than mean of the 24 added variables and code 1 to participants achieving mean or above score. In the next stage we used logistic regression univariate enter method to measure univariate association between 3 dependent variables and socio-demographic variables of the participants. Variables with p-value cut-off point of $<0.25$ was then included to multivariable analysis for controlling for the confounding factors.

\section{RESULTS}

We found an almost linear relationship between the knowledge and practice of the sample $(r=0.541$ and $\mathrm{P}=<0.001$ ) signifying that the increase in knowledge of health workers about HCWM was positively related with their practices (Figure I). However, such a correlation was not observed between knowledge and attitude. 
Ramesh Kumar, Ratana Somrongthong, Jamil Ahmed, Amer Jebril Almarabheh

Knowledge of health workers across sociodemographic variables including age, gender, ethnic origin, type of the hospital, department within the hospital, occupation and years of experience was compared and statistically significance and independent associations were assessed with the outcome after adjustment for their confounding effects in the multivariate model. Health workers in younger age groups compared to those equal to or more than 35 years of age, male compared to female workers, health workers with Sindhi and Balochi ethnic origins and paramedics compared to nurses had less odds of achievement of mean HCWM knowledge score $(P=<0.05)$. On the contrary, operation theatre workers compared to workers within other departments had 25 times more likelihood of achieving higher HCWM knowledge scores $(P=<0.05)$. In the case of healthcare waste handling in hospital environment, paramedical staff had more knowledge in contrast to physicians and nurses $(P=<0.001)$. Other variables such as, years of experience of health workers was found to draw no associations with the knowledge score within our multivariate model (Table I).

Next, we measured the attitude of health workers across socio-demographic variables like age, gender and ethnicity of the health workers, hospital type, department, occupation and experience. After adjustment, we found that health workers in younger age groups compared to equal to and more than 35 years of age, males as compared to females, Sindhi and Balochi ethnic health workers and paramedics as compared to nurses were less likely to achieve mean score on attitude about HCWM; however, this result was statistically insignificant $(P>0.05)$. Health workers with 5-10 years of experience of working within the hospitals compared to less than 5 or more than 10 years of experience were 4 times more likely to have positive attitude about HCWM $(P=<0.02)$. We found that physicians had positive attitudes towards HCWM compared to paramedics and nursing staff $(P=<0.001)$ (Table II).

Lastly, we measured how these socio-demographic variables were associated with the practices of health workers around HCWM. Young health workers of less than 35 years compared to those 35 years or more, male compared to female workers, Sindhi and Balochi ethnic origin health workers and paramedics in comparison to were less likely to gain mean HCWM practice related score $(P=<0.05)$. Consistent with the results obtained with the outcomes on knowledge and

\section{TABLE I: KNOWLEDGE WITH SOCIO-DEMOGRAPHIC VARIABLES BY USING MULTIVARIATE LOGISTIC} REGRESSION ANALYSIS ( $\mathrm{n}=\mathbf{2 7 5})$

\begin{tabular}{|c|c|c|c|c|}
\hline \multicolumn{2}{|c|}{ Socio-demographic Variables } & \multirow{2}{*}{$\frac{\text { OR }^{\text {unadj (95\% C.I.) }}}{1.55(0.8-3.02)}$} & \multirow{2}{*}{$\begin{array}{c}\text { OR }^{\text {adj }} \text { (95\% C.I.) } \\
0.10(0.01-0.68)\end{array}$} & \multirow{2}{*}{$\frac{\text { P value }}{0.018}$} \\
\hline Age & $<25$ & & & \\
\hline & $25-35$ & $1.02(0.47-2.25)$ & $0.12(0.02-0.76)$ & 0.024 \\
\hline & $>35$ & 1 & 1 & \\
\hline \multirow[t]{2}{*}{ Gender } & Male & $0.25(0.13-0.45)$ & $0.18(0.04-0.88)$ & 0.035 \\
\hline & Female & 1 & 1 & \\
\hline \multirow[t]{4}{*}{ Ethnicity } & Punjabi & $1.04(0.46-2.37)$ & $0.21(0.24-1.88)$ & 0.165 \\
\hline & Sindhi & $0.97(0.22-4.24)$ & $0.01(0.00-0.40)$ & 0.013 \\
\hline & Balochi & $0.64(0.11-3.80)$ & $0.03(0.002-0.70)$ & 0.029 \\
\hline & Pathan & 1 & 1 & \\
\hline \multirow[t]{2}{*}{ Hospital } & Holy Family Hospital & $1.01(0.58-1.75)$ & $0.85(0.26-2.98)$ & 0.894 \\
\hline & District Head quarter Hospital & 1 & 1 & \\
\hline \multirow[t]{7}{*}{ Departments } & Medicine ward & $1.75(0.73-4.18)$ & $0.95(0.19-4.60)$ & 0.956 \\
\hline & Surgical ward & $1.60(0.58-4.36)$ & $1.71(0.26-11.16)$ & 0.572 \\
\hline & Gynecology ward & $3.30(1.28-8.45)$ & $1.10(0.22-5.40)$ & 0.901 \\
\hline & Emergency & $1.75(0.68-4.48)$ & $1.05(0.19-5.75)$ & 0.952 \\
\hline & Administration & $0.80(0.18-3.42)$ & $0.98(0.01-55.57)$ & 0.995 \\
\hline & Operation Theater & $1.00(0.35-2.83)$ & $25.98(1.08-623.18)$ & 0.045 \\
\hline & Other & 1 & 1 & \\
\hline \multirow[t]{3}{*}{ Occupation } & Doctor & $1.20(0.52-2.73)$ & $2.71(0.61-12.01)$ & 1.288 \\
\hline & Paramedics & 0.00 & $0.002(0.00-0.53)$ & $<0.001$ \\
\hline & Nursing staff & 1 & 1 & \\
\hline \multirow[t]{3}{*}{ Experience } & $<5$ years & $3.45(1.55-7.63)$ & $4.30(0.81-0.00)$ & 0.085 \\
\hline & $5-10$ years & $0.54(0.26-1.11)$ & $0.56(0.12-2.50)$ & 0.452 \\
\hline & $>10$ years & 1 & 1 & \\
\hline
\end{tabular}


attitude we found that operation theatres health workers had 25 times more odds of good HCWM practices in comparison to staff working within other hospital departments $(P=<0.05)$. of Paramedical staff had higher odds of mean score in better practices for handling of waste in hospitals compared to physicians and nursing staff $(\mathrm{P}=<0.001)$ (Table III).

FIGURE I: SCATTER/DOT GRAPH SHOWING PEARSON CORRELATION BETWEEN KNOWLEDGE AND PRACTICE OF HEALTH WORKERS

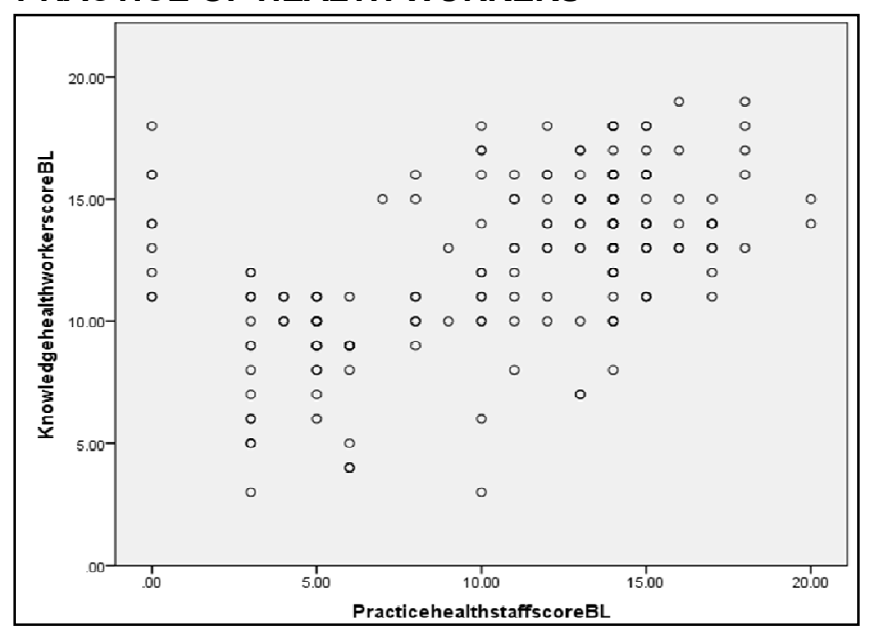

\section{DISCUSSION}

This study aimed to determine the factors that could potentially influence the health workers' KAP (Knowledge, Attitudes and Practices) about HCWM, based upon these findings a solution may be recommend enabling health workers, mainly in low/ middle income countries, to handle hospital waste appropriately and prevent potential hospital acquired infections or other environment related problems arising from the disorganised waste disposal. We found that males, those in younger age groups, paramedics and those working in operation theatres were more knowledgeable and showed positive attitudes and practices except that physicians had better practices regarding waste management. Our findings were supported by similar study that identified, the knowledge among workers working in operation theatres is significantly high as compare to others ${ }^{14}$. We, also found a significant internal consistency in our results which showed that knowledge about various aspects of waste management reflects as positive attitude and behaviour of the workers; which is consistent with current theory of planned behaviour ${ }^{15}$.

This study suggested that the working environment and provider related factors are important in quality of

TABLE II: ATTITUDE WITH SOCIO-DEMOGRAPHIC VARIABLES BY USING MULTIVARIATE LOGISTIC REGRESSION ANALYSIS ( $n=275)$

\begin{tabular}{|c|c|c|c|c|}
\hline \multicolumn{2}{|c|}{ Socio-demographic Variables } & $\mathrm{OR}^{\text {unadj }}(95 \%$ C.I.) & $\mathrm{OR}^{\mathrm{adj}}(95 \%$ C.I. $)$ & $P$ value \\
\hline \multirow[t]{3}{*}{ Age } & $<25$ & $0.51(0.26-1.00)$ & $0.32(0.09-1.14)$ & 0.079 \\
\hline & $25-35$ & $0.99(0.43-2.23)$ & $0.81(0.21-3.04)$ & 0.764 \\
\hline & $>35$ & 1 & 1 & \\
\hline \multirow[t]{2}{*}{ Gender } & Male & $0.18(0.10-0.33)$ & $0.39(0.09-1.68)$ & 0.209 \\
\hline & Female & Reference & Reference & \\
\hline \multirow[t]{4}{*}{ Ethnicity } & Punjabi & $3.03(1.29-7.08)$ & $1.51(0.33-6.90)$ & 0.593 \\
\hline & Sindhi & $4.92(1.02-23.62)$ & $1.35(0.12-14.21)$ & 0.801 \\
\hline & Balochi & $4.22(0.64-27.49)$ & $1.33(0.03-46.63)$ & 0.873 \\
\hline & Pathan & 1 & 1 & \\
\hline \multirow[t]{2}{*}{ Hospital } & Holy Family Hospital & $1.05(0.61-1.80)$ & $0.77(0.23-2.53)$ & 0.667 \\
\hline & District Head quarter Hospital & 1 & 1 & \\
\hline \multirow[t]{7}{*}{ Department } & Medical ward & $0.31(0.12-0.76)$ & $0.30(0.06-1.49)$ & 0.144 \\
\hline & Surgical ward & $0.48(0.17-1.33)$ & $1.01(0.17-5.86)$ & 0.985 \\
\hline & Gynecology ward & $1.93(0.76-4.92)$ & $2.44(0.41-14.47)$ & 0.325 \\
\hline & Emergency & $1.16(0.45-3.01)$ & $0.65(0.13-3.26)$ & 0.607 \\
\hline & Administration & $1.33(0.29-6.11)$ & $1.50(0.08-25.70)$ & 0.777 \\
\hline & Operation Theater & $1.16(0.39-3.41)$ & $0.56(0.08-3.66)$ & 0.551 \\
\hline & Other & 1 & 1 & \\
\hline \multirow[t]{3}{*}{ Occupation } & Doctor & $0.00(0.001-0.01)$ & $0.00(0.001-0.02)$ & $<0.001$ \\
\hline & Paramedics & $0.15(0.05-0.04)$ & $0.22(0.05-1.03)$ & 0.055 \\
\hline & Nursing staff & 1 & 1 & \\
\hline \multirow[t]{3}{*}{ Experience } & $<5$ years & $0.28(0.13-0.60)$ & $2.96(0.61-14.24)$ & 0.175 \\
\hline & $5-10$ years & $0.86(0.40-1.85)$ & $4.77(1.26-17.99)$ & 0.021 \\
\hline & $>10$ years & 1 & 1 & \\
\hline
\end{tabular}


Ramesh Kumar, Ratana Somrongthong, Jamil Ahmed, Amer Jebril Almarabheh TABLE III: PRACTICES WITH SOCIO-DEMOGRAPHIC VARIABLES BY USING MULTIVARIATE LOGISTIC
REGRESSION ANALYSIS ( $\mathrm{n}=275)$

\begin{tabular}{|c|c|c|c|c|}
\hline \multicolumn{2}{|c|}{ Socio-demographic Variables } & \multirow{2}{*}{$\begin{array}{r}\text { OR }^{\text {unadj }}(95 \% \text { C.I.) } \\
0.93(0.47-1.85)\end{array}$} & \multirow{2}{*}{$\begin{array}{c}\mathbf{O R}^{\text {adj }}(\mathbf{9 5} \% \text { C.I. }) \\
0.10(0.01-0.68) \\
\end{array}$} & \multirow{2}{*}{$\begin{array}{r}\text { P value } \\
0.018\end{array}$} \\
\hline Age & $<25$ & & & \\
\hline & $25-35$ & $0.38(0.17-0.86)$ & $0.12(0.02-0.76)$ & 0.024 \\
\hline & $>35$ & 1 & 1 & \\
\hline \multirow[t]{2}{*}{ Gender } & Male & $0.24(0.13-0.43)$ & $0.18(0.04-0.88)$ & 0.035 \\
\hline & Female & 1 & 1 & \\
\hline \multirow[t]{4}{*}{ Ethnicity } & Punjabi & $0.42(0.16-1.09)$ & $0.21(0.02-1.88)$ & 0.165 \\
\hline & Sindhi & $0.11(0.02-0.59)$ & $0.01(0.00-0.40)$ & 0.013 \\
\hline & Balochi & $0.13(0.02-0.93)$ & $0.03(0.002-0.70)$ & 0.029 \\
\hline & Pathan & 1 & 1 & \\
\hline \multirow[t]{2}{*}{ Hospital } & Holy Family Hospital & $0.97(0.56-1.68)$ & $0.89(0.26-2.98)$ & 0.856 \\
\hline & District Head quarter Hospital & 1 & 1 & \\
\hline \multirow[t]{7}{*}{ Department } & Medical ward & $2.36(0.14-3.76)$ & $0.95(0.19-4.60)$ & 0.956 \\
\hline & \begin{tabular}{|l|} 
Surgical ward \\
\end{tabular} & $1.50(0.97-5.75)$ & $1.71(0.26-11.16)$ & 0.572 \\
\hline & Gynecology ward & $3.21(0.55-4.07)$ & $1.10(0.22-5.40)$ & 0.901 \\
\hline & Emergency & $1.50(1.27-8.10)$ & $1.050 .19-5.75)$ & 0.952 \\
\hline & Administration & $1.38(0.59-3.79)$ & $0.98(0.01-55.57)$ & 0.995 \\
\hline & \begin{tabular}{|l} 
Operation Theater \\
\end{tabular} & $1.32(0.32-5.91)$ & $25.98(1.08-623.18)$ & 0.045 \\
\hline & Other & 1 & 1 & \\
\hline \multirow[t]{3}{*}{ Occupation } & Doctor & $1.65(0.72-3.73)$ & $2.71(0.61-12.01)$ & 0.189 \\
\hline & Paramedics & $0.005(0.001-0.04)$ & $0.002(0.00-0.05)$ & $<0.001$ \\
\hline & Nursing staff & 1 & 1 & \\
\hline \multirow[t]{3}{*}{ Experience } & $<5$ years & $2.90(1.26-6.68)$ & 4.306 & 0.085 \\
\hline & $5-10$ years & $0.27(0.12-0.56)$ & $0.56(0.12-2.50)$ & 0.452 \\
\hline & $>10$ years & 1 & 1 & \\
\hline
\end{tabular}

care that depends on the Knowledge and technical skills of health worker ${ }^{16}$. Studies have consistently showed that health workers in developing countries have significantly lower knowledge of HCWM; however we analysed, in the present study, only the comparison of KAP among various subgroups and cadres of health workers. A statistically significant and positive correlation between knowledge and practice of the participants means that workers would be able to effectively follow the HCWM guidelines and implement in their practices if their knowledge level is significantly high. Although, we found significantly higher knowledge of healthcare waste management related guidelines among males and young health professionals, our results about the relationship of personal factors such as age and gender of the participants reflected less agreement with similar literature in which these factors were not shown to affect the health workers' knowledge or behaviour towards HCWM ${ }^{17}$.

Our study is consistent with the literature, which shows that paramedics working in hospitals have better knowledge and show optimum behaviour towards waste management as compared to other staff such as nurses ${ }^{18}$. On the other hand, nurses had better KAP as compared to paramedical staff in our study. Studies have often combined the nursing and paramedical, such as sanitation staff ${ }^{19}$; we have, in our study, shown separate findings for these groups of workers. However our results are consistent with studies, form the region and outside ${ }^{20,21}$, which showed that physicians had better KAP as compared to nurses and later had better KAP than sanitation staff.

Younger health workers in our study had better KAP towards HCWM; we assume that this distinction could be because the younger workers strive to show their commitment to their work to sake of job insecurity. Females lagged males in their KAP; perhaps because it is the nurses, mostly females in our study, who take up most of the direct patient handling related tasks and they showed less KAP as compared to physicians in our study. This is significant since they are exposed to the contaminated tissues and items; they could be 
major source of transmission of hospital-acquired infections and prolonged hospital stay for the patients. Staff in operation theatres possessed better KAP, even if wards fail to follow proper waste management, operation theatres are better maintained and follow guidelines for infection prevention to some extent. Since other studies have also compared laboratory staff's KAP about HCWM and they are shown to have highest level of KAP, probably because of their proximity to biological specimens, whereas, we just focussed on staff working indoor in both the hospitals. Although studies have analysed and ranked hospitals for their overall standing with regard to $\mathrm{HCWM}^{3}$, we could only compare the two participating hospitals for their staff's adherence to HCWM related KAP. Interestingly the KAP of administrative staff was shown to be better than many other cadres, though the differences were not statistically significant. This suggests that the presence of learned workers could be an opportunity for other staff to learn.

\section{CONCLUSIONS}

We conclude that the socio demographic factors affect knowledge, attitude and practices among doctors, paramedics and nurses. Although better Knowledge, appropriate attitude and standard practices have been reported among the paramedics working in operation theatres; yet results are clearly suggestive of the need for continuing education on HCWM of all work groups in a hospital environment. Further research is required to understand as to how the differences in KAP among various groups of health workers be eliminated and, more importantly, how health workers with better KAP can influence and help their fellow workers, especially paramedical staff, to engage in optimum HCWM practices.

\section{ACKNOWLEDGMENT}

This research is supported by Rachadapisek Sompote Fund for Postdoctoral Fellowship, Chulalongkorn University Thailand.

\section{REFERENCES}

1. Shi $H$, Liu HC, Li $P, X u X G$. An integrated decision making approach for assessing healthcare waste treatment technologies from a multiple stakeholder. Waste Management (New York N.Y). 2016; 59:508-17.

2. Kumar R, Somrongthong $\mathrm{R}$, Shaikh $\mathrm{BT}$. Effectiveness of intensive healthcare waste management training model among health professionals at teaching hospitals of Pakistan: a quasi-experimental study. BMC Health Serv Res. 2015; 15:81.

3. Malekahmadi F, Yunesian $M$, Yaghmaeian $\mathrm{K}$,
Nadafi K. Analysis of the healthcare waste management status in Tehran hospitals. J Environ Health Sci Eng. 2014; 12(1):116.

4. Tudor TL, Woolridge AC, Phillips CA, Holliday M, Laird $\mathrm{K}$, Bannister $\mathrm{S}$, et al. Evaluating the link between the management of clinical waste in the National Health Service (NHS) and the risk of the spread of infections: A case study of three hospitals in England. Int $\mathrm{J}$ Hyg Environ Health. 2010;213(6):432-6.

5. Prüss A, Giroult E, Rushbrook P. Safe Management of Wastes from Health-Care Activities. Geneva: World Health Organization; 1999.

6. de Titto E, Savino AA, Townend WK. Healthcare waste management: the current issues in developing countries. Waste Management \& Research. 2012; 30(6):559-61.

7. Kumar R, Somrongthong R, Ahmed J. Impact of waste management training intervention on knowledge, attitude and practices of teaching hospital workers in Pakistan. Pak J Med Sci. 2016; 32(3):705-10.

8. Paudel R, Pradhan B. Health care waste management practice in a hospital. J Nepal Health Res Counc. 2010;8(2):86-90.

9. Bhagawati G, Nandwani S, Singhal S. Awareness and practices regarding bio-medical waste management among health care workers in a tertiary care hospital in Delhi. Indian $\mathrm{J}$ Med Microbiol. 2015; 33(4):580-2.

10. Kumar R, Khan EA, Ahmed J, Khan Z, Magan M, Nousheen, et al. Healthcare waste management (HCWM) in Pakistan: current situation and training options. J Ayub Med Coll Abbottabad. 2010; 22 (4):101-6.

11. Kumar R, Samrongthong $R$, Shaikh BT. Knowledge. attitude and practices of health staff regarding infectious waste handling of tertiary care health facilities at metropolitan city of Pakistan. J Ayub Med Coll Abbottabad. 2013; 25 (1-2):109-12.

12. Tabash MI, Hussein RA, Mahmoud AH, El-Borgy MD, Abu-Hamad BA. Impact of an educational program on knowledge and practice of health care staff toward pharmaceutical waste management in Gaza, Palestine. J Air Waste Manag Assoc. 2016; 66(4):429-38.

13. Hill T, Lewicki P. (2007). STATISTICS Methods and Applications. Tulsa, OK: Statsoft Web: http:// www.statsoft.com/textbook.

14. Hassan AN, Hassan AM, Abdrahman AA, Elshallaly $\mathrm{GH}$, Saleh MA. Assessment of existing practices in the operating theatre in the Khartoum North Teaching Hospital, Sudan. South Afr J 
Epidemiol Infect. 2011; 26(2):79-82.

15. Akulume M, Kiwanuka SN. Health Care Waste Segregation Behavior among Health Workers in Uganda: An Application of the Theory of Planned Behavior. J Environ Public Health. 2016; 2016:8132306.

16. Mosadeghrad AM. Factors influencing healthcare service quality. Int J Health Policy Manag. 2014;3 (2):77-89.

17. Makhura RR, Matlala SF, Kekana MP. Medical waste disposal at a hospital in Mpumalanga Province, South Africa: Implications for training of healthcare professionals. South Afr Medical J. 2016;106(11):1096-1102.

18. Enwere OO, Diwe KC. Knowledge, perception and practice of injection safety and healthcare waste management among teaching hospital staff in south east Nigeria: an intervention study. Pan
Afr Med J. 2014; 17:218.

19. Elnour AM, Moussa MM, El-Borgy MD, Fadelella $\mathrm{NE}$, Mahmoud AH. Impacts of health education on knowledge and practice of hospital staff with regard to Healthcare waste management at White Nile State main hospitals, Sudan. Int J Health Sci (Qassim). 2015; 9(3):315-31.

20. Galimany-Masclans J, Torres-Egea $P$, SanchoAgredano R, Girbau-Garcia MR, Fabrellas N, Torrens-Garcia ML, et al. [Management of Healthcare Waste in the Hospital Setting. Understanding Risk Management]. Rev Enferm. 2015; 38(5):14-9.

21. Mathur V, Dwivedi S, Hassan MA, Misra RP. Knowledge, Attitude, and Practices about Biomedical Waste Management among Healthcare Personnel: A Cross-sectional Study. Indian J Community Med. 2 011; 36(2):143-5.

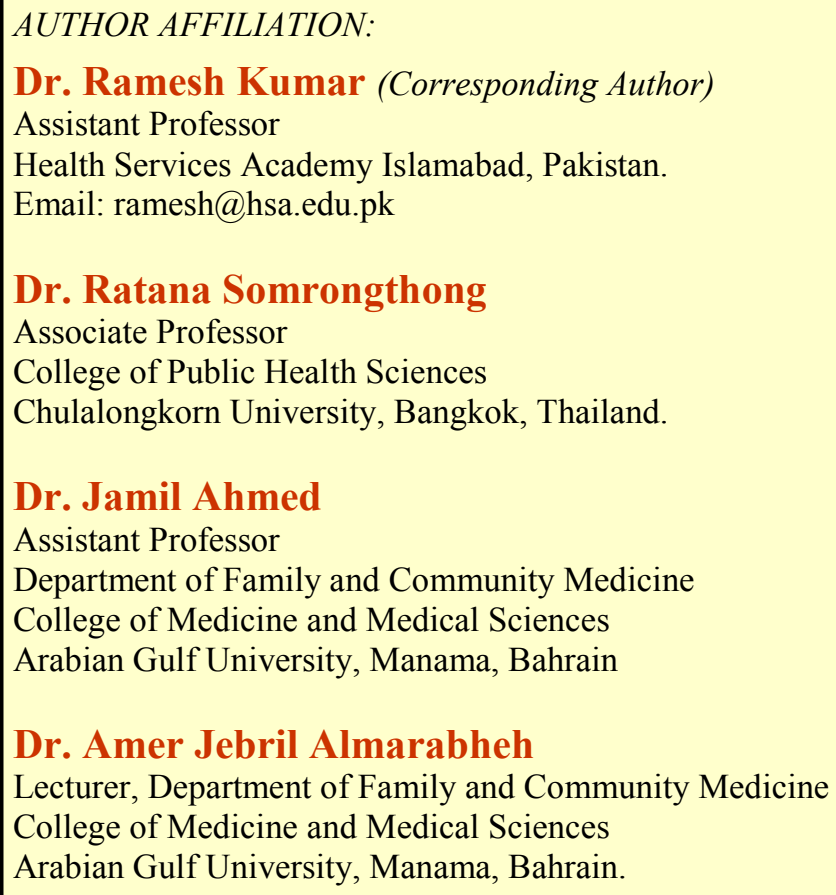

